\title{
Multivariate Assessment of Marginal Fit of Three Types of Dental Crowns Using Three Scanning Systems for CAD-CAM Technology - in vitro Pilot Study
}

\begin{abstract}
SMARANDA BUDURU', ANCA MESAROS ${ }^{2 *}$, CRISTIAN CULCITCH ${ }^{3}$, MARIOARA MOLDOVAN ${ }^{4}$, DOINA PRODAN4, CAMELIA SZUHANE ${ }^{5}$

Iuliu Hatieganu University of Medicine and Pharmacy, Department of Prosthodontics, 32 Clinicilor Str., 400006, Cluj Napoca, Romania

2ulliu Hatieganu University of Medicine and Pharmacy, Department of Dental Propaedeutics and Esthetics, 32 Clinicilor Str., 400006, Cluj Napoca, Romania

3uluiu Hatieganu University of Medicine and Pharmacy, Department of Periodontology, 15 Babes Str., 400006, Cluj Napoca, Romania

${ }^{4}$ Babes Bolyai University, Raluca Ripan Chemistry Research Institute, Department of Polymer Composites, 30 Fantanele Str., 400294, Cluj Napoca, Romania

5Victor Babes University of Medicine and Pharmacy Timisoara, Faculty of Dental Medicine, 2 Eftimie Murgu Sq., 300041, Timisoara, Romania

The objective of this in-vitro study was to compare if there are any differences in the marginal fit of crowns fabricated by CAD/CAM technique. We used three different types of materials (two types of polymethylmetacrylate (PMMA) provided by two different manufacturers and one type of hybrid ceramic) and three different types of impressions: intraoral scanning, model scanning and conventional impression scanning. The crowns were subsequently measured with an electronic microscope at 1000X. Our results showed better results for the hybrid ceramic. The differences between the PMMA were not significant. There were no statistic differences with the ANOVA analysis between the scanning methods. Best combination in terms of marginal fit was found with hybrid ceramic and intraoral scanning.
\end{abstract}

Keywords: marginal fit, intraoral scanner, model scanner, impression scanning, PMMA, hybrid ceramic, SEM

Currently, there is an ongoing development of computer technology and consequently digital manufacturing is more present in the dental office workflow as it brings multiple advantages in the field of fixed prosthodontics. Conventional approach involved conventional impressions, stone-model casting and dental reconstructions manufacturing using the lost-wax technique. The available CAD/CAM (Computer-aided design and computer-aided manufacturing) systems allow a digital workflow from the very beginning of the impression taking. It is continued with a digital design of the future restoration and, by computer aided manufacturing, the restorations are milled or 3D-printed. The advantages of this digital workflow are related to high precision and reproducibility of the endproduct results, while also reducing manpower in the dental technician laboratory [1].

Due to all their advantages CAD/CAM dental restorations are growing increasingly popular. Nowadays, the research related to this system has also focused on providing information for clinicians regarding newer materials for single-unit restorations in both provisional and long-term prosthetics [2].

However, the clinical success of any dental restoration is influenced by several factors such as the mechanical properties, aesthetic quality, and biocompatibility of the materials used, but also by accurate design and marginal fit of the prosthetic piece. Marginal gaps of certain values cause failure of a restoration by dissolving dental cement so quickly that dental plaque easily accumulates, leading to marginal leakage and favoring secondary caries [3,717].

\footnotetext{
*email: ancames@yahoo.com, mesaros.anca@umfcluj.ro
}

Several in vitro and in vivo studies on marginal fit of dental restorations have proven that a marginal discrepancy (MD) can be one of the major factors causing secondary caries and periodontal diseases. McLean proved in 1971 that a clinically acceptable marginal fit is within the $120 \mu \mathrm{m}$ range when fabricating a dental restoration [4]. Martiinez-Rus reported that CAD/CAM ceramic crowns have a clinically acceptable of marginal gap of 17 to $118 \mu \mathrm{m}$ [5]. They also recommend using chamfer margins and shoulder margins to fabricate the precise anatomic contour of the crowns [6]. In a systematic review, Boitelle et al reported thatCAD/ CAM technology provides dental prostheses with MD values less than 80um [18].

Regarding the behavior of newer dental restoration materials that are CAD/CAM compatible, there is still a lack of knowledge for the clinicians. Our in-vitro pilot study is designed to answer some of the questions arising for the clinicians.

The present study aims to compare the marginal adaptation of three crowns made up of three different types of material (two sets of PMMA crowns from different manufacturers and one set of hybrid ceramic) obtained by three different scanning processes. The following hypotheses were tested:

1. Is the marginal adaptation influenced by the type of material when working under the same scanning and milling conditions?

2. Is the marginal fit dependent on the type of scan while using the same material?

3. Which is the most advantageous combination of materials and scanning technique in terms of marginal adaptation for better clinical results? 


\section{Experimental part}

An experimental object in the form of a stump was manufactured using an AG-3 Standard Restorative Typodont (Frasaco, USA) model of a permanent maxillary left first molar (tooth 2.6 according to the IDF classification), which was prepared for all ceramic crowns by applying the following preparatory principles: $1.5 \mathrm{~mm}$ axial and proximal surface reduction, $10^{\circ}$ occlusal convergence, 2 $\mathrm{mm}$ occlusal reduction, $1 \mathrm{~mm}$ rounded chamfer margin.

The first scan (S1) was performed with the TRIOS 3 intraoral scanner (3Shape, Denmark). Scanning of the upper arch, lower arch (as the antagonistic jaw) and occlusion for the Typodont were performed. STL files were sent via the Internet to the dental laboratory (fig. 1).

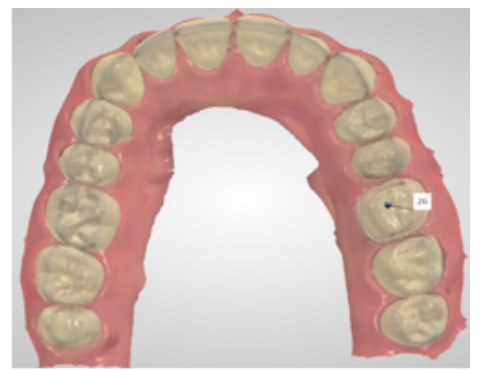

Fig. 1. Intraoral scanning (S1)

The same models were sent to the same dental laboratory where a second scan (S2) was performed. This was done with the 3Shape E3 Model Scanner (3Shape, Denmark) (fig. 2).

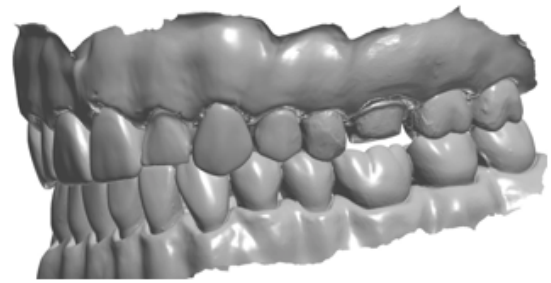

Fig. 2. Model Scanning

(S2)

Thirdly, a conventional impression using polivynilsiloxane (Elite HD+, putty soft and light body, Zhermack) in a standard metallic impression tray was done on the Typodont. The impression was scanned (S3) using the 3Shape E3 (3Shape, Denmark) model scanner. (fig.3)

The 3 scans produced 3 virtual models (M1, M2, M3) that were used by the same operator to design 3 virtual crowns $(\mathrm{C} 1, \mathrm{C} 2, \mathrm{C} 3)$ using the same design parameters (cement gap 0,02 mm, extra-cement gap $0.04 \mathrm{~mm}$, vertical margin gap $0.0001 \mathrm{~mm}$ ). The software that was used for the design was Dental Designer (fig. 4).

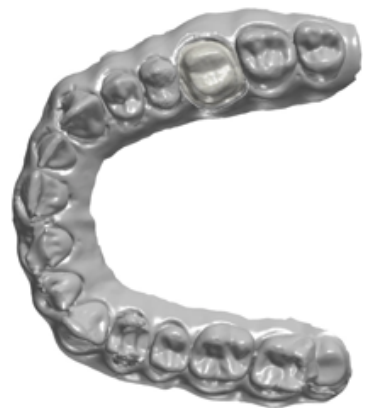

Fig. 3. Scanning of the conventional impression

Each of the three virtual crowns was milled 3 times, using the three different materials: two sets of PMMA crowns from different manufacturers and one set of hybrid ceramic, achieving 9 different crowns in the end (fig. 5).

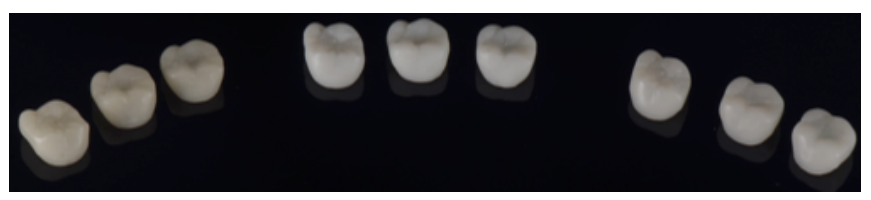

Fig. 5. The 9 crowns from the three different materials

The materials that were milled are:

-PMMA disc, $18 \mathrm{~mm}$ width, $98.5 \mathrm{~mm}$ diameter, shade A2 (Bilkim, Turkey);

-PMMA disc, 16mm width, $98.5 \mathrm{~mm}$ diameter, shade BL2 (ZCAD ${ }^{\text {TM }}$ TempEstetic Fix ${ }^{\text {TM }}$ Provisional PMMA Material for Wieland $₫$ - Harvest Dental);

-Glass ceramic in a resin-interpenetrating matrix (Enamic, Vita) blocks, 2M3-T EM-14 (Vita, Germany). This is composed of a dual network: a feldspathic ceramic network ( $86 \%$ by weight/75\% by volume) and a polymer network ( $14 \%$ by weight/25\% by volume). The specific composition of the ceramic part is $58 \%$ to $63 \% \mathrm{SiO}, 20 \%$ to $23 \% \mathrm{Al}_{2} \mathrm{O}_{3}, 9 \%$ to $11 \% \mathrm{Na}_{2} \mathrm{O}, 4 \%$ to $6 \% \mathrm{~K}_{2} \mathrm{O}, 0.5 \%$ to $2 \%$ $\mathrm{B}_{2} \mathrm{O}_{3}$ less than $1 \%$ of $\mathrm{Zr}{ }_{2} \mathrm{O}$ and $\mathrm{CaO}$. The polymer network is composed of urethane dimethacrylate (UDMA) and triethylene glycol dimethacrylate (TEGDMA). The manufacturer refers to this as a hybrid ceramic [19].

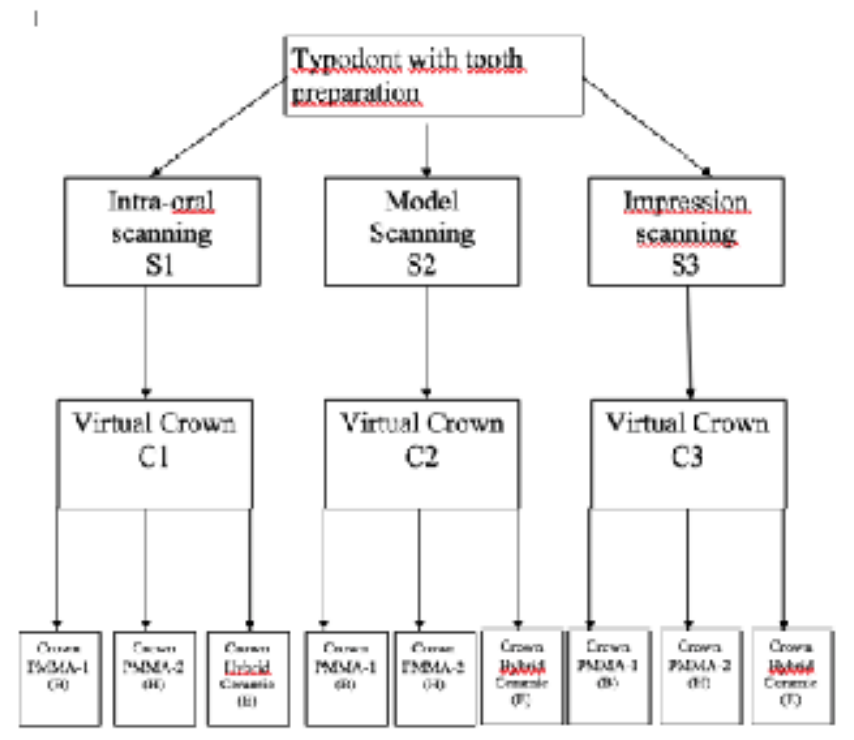

Fig.6. Design of the study

After milling the abutment was unscrewed from the model, and using a permanent marker signs in the middle of each axial surface (mesial, distal, oral, buccal) were drawn just below the marginal preparation on the root surface. Each crown was fixed to the abutment with temporary cement (TempBond Clear, Kerr) applied in a very small amount in the middle of the occlusal face of the crown.

Each crown was examined at the FEl Quanta Inspect FP 2017/11 (FEl, Czech Republic) scanning electron microscope and the marginal fit was assessed at each of the 4 points mentioned above by measuring the gap between the cervical limit of the preparation on the abutment and the crown. The magnification used was $1000 x$.

\section{Results and discussions}

The raw results of our measurements are presented in table 1. All measurements were done in triplicate and the table shows the mean values.

Regarding the scanning methods for intraoral scanning, the best marginal fit value was obtained in the case of the Enamic hybrid ceramic crown on the mesial surface (4.08 
Table 1

RAW RESULTS OF THE MICROSCOPIC ANALYSIS OF THE MARGINAL

\begin{tabular}{|c|c|c|c|c|c|}
\hline \multicolumn{6}{|c|}{ FIT } \\
\hline & & Distal & Mesial & Palatal & Buccal \\
\hline \multirow{3}{*}{ Bilkim (B) } & I.O. & 195.24 & 139.58 & 166.10 & 57.41 \\
\hline & Model & 167.39 & 67.13 & 111.41 & 118.13 \\
\hline & Impression & 186.50 & 132.10 & 112.74 & 136.67 \\
\hline \multirow{3}{*}{ Harvest $(\mathrm{H})$} & I.O & 148.94 & 159.81 & 150.71 & 96.43 \\
\hline & Model & 58.28 & 88.3 & 23.6 & 67.9 \\
\hline & Impression & 122.68 & 249.23 & 210.10 & 224.67 \\
\hline \multirow{3}{*}{ Enamic (E) } & I.O & 73.55 & 4.08 & 76.35 & 56.76 \\
\hline & Model & 53.35 & 50.08 & 140.46 & 48.10 \\
\hline & Impression & 90.44 & 69.54 & 16.77 & 11.47 \\
\hline
\end{tabular}

microns) and the worst was in case of the Bilkim PMMA crown on the distal surface (195.24 microns). For model scanning, the best marginal fitwas obtained for the Harvest Dental PMMA crown on the palatal surface ( 23.60 microns), and the worst fit was for the Bilkim PMMA crown on the distal surface (167.39 microns). For conventional impression scanning, the best marginal fit was obtained for the Enamic crown on the buccal surface (11.47 microns), and the worst fit was in the case of the Harvest Dental PMMA crown on the distal surface (249.23 microns).

Regarding the materials, for Enamic Crowns, the best value found was on the mesial surface at intraoral scanning ( 4.08 microns) and the worst value on the palatal surface on model scanning (140.46 microns). In the case of the Bilkim PMMA crowns, the best value found was with intraoral scanning on the buccal surface (57.41 microns) and the worst at intraoral scanning on the distal surface (195.24 microns). In the case of the Harvest Dental PMMA crowns, the best value found was with model scanning on the oral surface (23.60 microns) and the worst for impression scanning on the mesial surface (249.23 microns) (figs. 7-10).

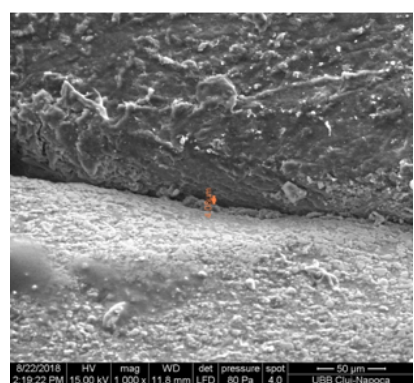

Fig. 7. Enamic: intraoral scanning (mesial)

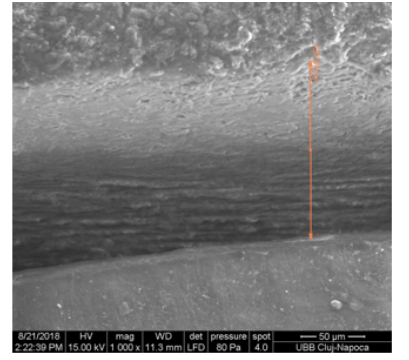

Fig. 9. Bilkim: impression scanning (oral)

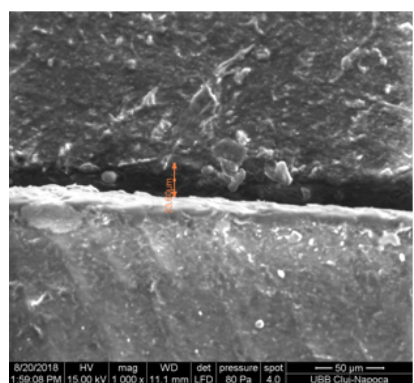

Fig. 8. Harvest Dental: model scanning (oral)

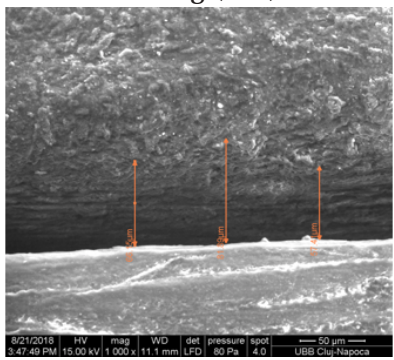

Fig. 10. Bilkim: intraoral scanning (buccal)

ANOVA statistical analysis reflects the fact that the statistical confidence level of $5 \%$ is not reached. The only exception is the evaluation done according to the material used, where measurements carried out on the distal surface had a $p$ value of less than 0.01 . In table II we displayed the mean values and the standard deviation for each surface.

For example, in the case of Enamic one can find the lowest mean values, but even so these values are quite high ( 72 microns distally or 78 microns palatally), and the palatal measurements show values that are quite scattered and the standard deviation is high (62).

Concerning the scanning method, data is not very conclusive, and we cannot draw a conclusion that one method is necessarily better than the other ( fact confirmed by the ANOVA test from SPSS).

For example, the mean fit on the buccal surface (i.e. for all 3 types of materials) has the lowest value in the case of intraoral scanning - however, the value is high (70 microns), but the standard deviation is reasonable (23).

Enamic crowns were used as representative for hybrid ceramic materials as a study from Yldirim et al stated that

\begin{tabular}{|c|c|c|c|c|c|c|c|c|}
\hline Material & $\begin{array}{c}\text { Mean } \\
\text { adaptation - } \\
\text { Distal }\end{array}$ & $\begin{array}{l}\text { Standard } \\
\text { deviation - } \\
\text { Distal }\end{array}$ & $\begin{array}{c}\text { Mean } \\
\text { adaptation - } \\
\text { Mesial }\end{array}$ & $\begin{array}{c}\text { Standard } \\
\text { deviation - } \\
\text { Mesial }\end{array}$ & $\begin{array}{c}\text { Mean } \\
\text { adaptation - } \\
\text { Palatal }\end{array}$ & $\begin{array}{l}\text { Standard } \\
\text { deviation - } \\
\text { Palatal }\end{array}$ & $\begin{array}{c}\text { Mean } \\
\text { adaptation - } \\
\text { Buccal }\end{array}$ & $\begin{array}{c}\text { Standard } \\
\text { deviation - } \\
\text { Buccal }\end{array}$ \\
\hline Bilkim & 183.04 & 14.24 & 112.94 & 39.85 & 130.08 & 31.20 & 104.07 & 41.46 \\
\hline Harvest D. & 109.97 & 46.65 & 165.78 & 80.63 & 128.14 & 95.28 & 129.67 & 83.50 \\
\hline Enamic & 72.45 & 18.57 & 64.57 & 12.75 & 77.86 & 61.86 & 38.78 & 24.04 \\
\hline Method & $\begin{array}{c}\text { Mean } \\
\text { adaptation - } \\
\text { Distal }\end{array}$ & $\begin{array}{l}\text { Standard } \\
\text { deviation - } \\
\text { Distal }\end{array}$ & $\begin{array}{c}\text { Mean } \\
\text { adaptation - } \\
\text { Mezial }\end{array}$ & $\begin{array}{c}\text { Standard } \\
\text { deviation - } \\
\text { Mezial }\end{array}$ & $\begin{array}{c}\text { Mean } \\
\text { adaptation - } \\
\text { Palatinal }\end{array}$ & $\begin{array}{l}\text { Standard } \\
\text { deviation - } \\
\text { Palatinal }\end{array}$ & $\begin{array}{c}\text { Mean } \\
\text { adaptation - } \\
\text { Buccal }\end{array}$ & $\begin{array}{c}\text { Standard } \\
\text { deviation - } \\
\text { Buccal }\end{array}$ \\
\hline I.O. & 139.24 & 61.42 & 124.49 & 44.81 & 131.05 & 48.00 & 70.20 & 22.72 \\
\hline Impression & 133.21 & 48.89 & 150.29 & 91.22 & 113.20 & 96.67 & 124.27 & 107.14 \\
\hline Model & 93.01 & 64.47 & 68.50 & 19.15 & 91.82 & 60.84 & 78.04 & 36.10 \\
\hline
\end{tabular}

Table 2

MARGINAL FIT: MEAN AND

STANDARD

DEVIATION ON

EACH SURFACE 
the marginal and internal adaptation values were within a clinically acceptable range for all 3 hybrids and nanoceramics tested for their study [20].

Ahrberg et al stated that even though both intraoral and model scanning facilitate the fabrication of single crowns with clinically acceptable marginal fit, a significantly better marginal fit was noted with for the intraoral scanner, advantages of digital impressions being that they are also less time-consuming for the dental practitioner and the patient [21]. Zhan et al found a significant difference between the marginal fit of the direct optical impression and scanning silicone rubber impression and cast models [22]. Gjevold et al demonstrated in their study that the digital technique was more efficient and convenient than the conventional impression technique [23]. Arzabala et al in their in vitro study found a very good marginal fit for Enamic, equal to other hybrid ceramics and better than glass ceramic [24].

\section{Conclusions}

The study concluded that the type of scanning did not have a significant statical influence on the marginal fit, the best results being obtained with the intraoral scanner. The material used for milling has been shown to influence the final result in terms of marginal fit on the abutment, the hybrid ceramic resin having performed much better than the PMMAs. Between the two PMMA discs used, the results were different even if the differences were not significant. The best combination achieved in the study was for Enamic crowns obtained after intraoral scanning on the mesial surface.

Some of the marginal gaps of PMMA materials were greater than 120 microns, which is considered to be the clinically acceptable maximum threshold value. This raises questions about the role of these types of provisional restorations in preserving periodontal health.

The limitations of the study are related to the small number of samples assessed, therefore it is highly recommended to increase the number of samples, the number of measurements for each sample and also to take other materials into consideration.

\section{References}

1.J ODA T, ZARONE F, FERRARI M, The complete digital workflow in fixed prosthodontics: a systematic review , BMC Oral Health (2017) 17:124 DOI 10.1186/s12903-017-0415-0

2.BATSON ER, COOPER LF, DUQUM I, MENDONÇA G. Clinical outcomes of three different crown systems with CAD/CAM technology. J Prosthet Dent. 2014 Oct;112(4):770-7

3.MIN-KYUNG JI ET ALL, Evaluation of marginal fit of 2 CAD-CAM anatomic contour zirconia crown systems and lithium disilicate glassceramic crown, J Adv Prosthodont 2015;7:271-7 http://dx.doi.org/ 10.4047/jap.2015.7.4.271

4.MCLEAN JW, VON FRAUNHOFER JA. The estimation of cement film thickness by an in vivo technique. Br Dent J 1971;131: 107-11.

5.MARTIINEZ-RUS F, SUAiREZ MJ, RIVERA B, PRADIES G. Evaluation of the absolute marginal discrepancy of zirconia-based ce- ramic copings. J Prosthet Dent 2011;105:108-14.

6.PERA P, GILODI S, BASSI F, CAROSSA S. In vitro marginal adaptation of alumina porcelain ceramic crowns. J Prosthet Dent 1994;72:585-90. 7.SAVENCU, CE, POROJAN, S, POROJ AN, L, Analysis of Internal and Marginal fit of Metal-ceramic Crowns During Processing, Using Conventional and Digitized Technologies, Rev. Chim.(Bucharest), 69, no. 7, 2018, p. 1699

8.BHASKARAN E, AZHAGARASAN NS, MIGLANI S, ILANGO T, KRISHNA GP, GAJAPATHI B., Comparative Evaluation of Marginal and Internal Gap of Co-Cr Copings Fabricated from Conventional Wax Pattern, 3D Printed Resin Pattern and DMLS Tech: An In Vitro Study, J Indian Prosthodontic Soc. 2013Sep;13(3):189-95
9.PARK J.Y., JEONG I.D., LEE J.J ., BAE S.Y, KIM J.H., KIM W.C., In vitro assessment of the marginal and internal fits of interim implant restorations fabricated with different methods, The Journal of Prosthetic Dentistry, 116(4), 2016, 536-542

10.POMPA G., DI CARLO S., DE ANGELIS F., CRISTALLI MP., ANNIBALI S., Comparison of conventional methods and laser-assisted rapid prototyping for manufacturing fixed dental prostheses: an in vitro study, BioMed Research International, Article ID 318097, 7 pages Vofgl.2015

11.NESSE H., UKERVIK ULSTEIN D.M., VAAGE M.M., OTILO M., Internal and marginal fit of cobalt-chromium fixed dental prostheses fabricated with 3 different techniques. Journal of Prosthetic Dentistry, Vol. 114(5) p 686-92.

12.NG J., RUSE D., WYATT C., A comparison of the marginal fit of crowns fabricated with digital and conventional methods, The J ournal of Prosthetic Dentistr y, Vol122(3), 2014, 555-560

13.POMPA G., DI CARLO S., DE ANGELIS F., CRISTALLI M.P., ANNIBALI S., Comparison of conventional methods and laser-assisted rapid prototyping for manufacturing fixed dental prostheses: an in vitro study, BioMed Research International

14.GUNSOY S., ULUSOY M., Evaluation of marginal/internal fit of chrome-cobalt crowns: Direct laser metal sintering versus computeraided design and computer-aided manufacturing, Nigerian J ournal of clinical Practice, vol.19(5), P 636-644

15.BACIU, S., BERECE, C., FLOREA, A., BURDE, A.V., NEGRUTIU, M.L., SZUHANEK,C., SINESCU, C., DUMA, V.F., MANOLE, M., A Comparative Three- and Bi-Dimensional Research Of The Marginal Fit Of Pressed Lithium Disilicate Inlays, Rev. Chim.(Bucharest), 68, no. 6, 2017, p. 1316

16.ANDREESCU, C.F., GHERGIC, D.L., BOTOACA, O., BARBU, H.M., CERNUSCA MITARIU, I.S., PATROI, D.N., The Advantages of High-density Polymer CAD/CAM Interim Restorations in Oral Implantology, Mat. Plast., 54, no.1, 2017, p. 32

17.SAVENCU, C.E., POROJAN, S., POROJAN, L., Analysis of Internal and Marginal fit of Metal-ceramic Crowns During Processing, Using Conventional and Digitized Technologies Rev. Chim. (Bucharest), 69, no. 7, 2018, p. 1699

18.BOITELLE P, MAWUSSI B, TAPIE L, FROMENTIN O. A systematic review of $C A D / C A M$ fit restoration evaluations. J Oral Rehabil 2014;41:853-74.

19.GRACIS S, THOMPSON VP, FERENCZ JL, SILVA N, BONFANTE E.A. A New Classi cation System for All-Ceramic and Ceramic-like Restorative Materials, The International J ournal of Prosthodontics, Volume 28, Number 3, 2015, 227-235.

20.YILDIRIM G, UZUN IH, KELES A Evaluation of marginal and internal adaptation of hybrid and nanoceramic systems with microcomputed tomography: An in vitro study, J Prosthet Dent. 2017 Aug;118(2):200207. doi: 10.1016/j.prosdent.2016.11.005. Epub 2017 J an 12

21.AHRBERG D, LAUER HC, AHRBERG, WEIGL P, Evaluation of fit and efficiency of CAD/CAM fabricated all- ceramic restorations based on direct and indirect digitalization: a double-blinded, randomized clinical trial, Clin Oral Investig. 2016 Mar;20(2):291-300. doi: 10.1007/s00784015-1504-6. Epub 2015J un 14

22.ZHAN L, ZENG L, CHEN P, LIAO L, LI S, LIU R, Study on the effect of different impression methods on the marginal fit of all-ceramic crowns , Hua Xi Kou Qiang Yi Xue Za Zhi. 2015 Aug;33(4):401-4

23.GJ ELVOLD B, CHRCANOVIC BR, KORDUNER EK, COLLINBAGEWITZ I, KISCH J. Intraoral Digital Impression Technique Compared to Conventional Impression Technique. A Randomized Clinical Trial.J Prosthodont. 2016 Jun;25(4):282-7. doi: 10.1111/ jopr.12410. Epub 2015 Nov 30.

24.AZARBAL A, AZARBAL M, ENGELMEIER RL, KUNKEL TC, Marginal Fit Comparison of CAD/CAM Crowns Milled from Two Different Materials.J Prosthodont. 2018J un;27(5):421-428. doi: 10.1111/jopr.12683. Epub 2017 Nov 16.

\section{Manuscript received: 11.06 .2018}

